\title{
Genomic Profiling of a Human Leukemic Monocytic Cell-Line (THP-1) Exposed to Alpha Particle Radiation
}

\author{
Vinita Chauhan and Matthew Howland \\ Consumer and Clinical Radiation Protection Bureau, Health Canada, Healthy Environment and Consumer Safety Branch, \\ Ottawa, ON, Canada K1A OK9 \\ Correspondence should be addressed to Vinita Chauhan, vinita_chauhan@hc-sc.gc.ca
}

Received 23 July 2012; Accepted 2 September 2012

Academic Editors: A. Alaiya, Y. Bai, A. S. Balajee, G. Bocci, and V. Krutovskikh

Copyright ( 12012 V. Chauhan and M. Howland. This is an open access article distributed under the Creative Commons Attribution License, which permits unrestricted use, distribution, and reproduction in any medium, provided the original work is properly cited.

\begin{abstract}
This study examined alpha $(\alpha-)$ particle radiation effects on global changes in gene expression in human leukemic monocytic cells (THP-1) for the purposes of mining for candidate biomarkers that could be used for the development of a biological assessment tool. THP-1 cells were exposed to $\alpha$-particle radiation at a dose range of 0 to $1.5 \mathrm{~Gy}$. Twenty-four hours and three days after exposure gene expression was monitored using microarray technology. A total of 16 genes were dose responsive and classified as early onset due to their expression $24 \mathrm{~h}$ after exposure. Forty-eight transcripts were dose responsive and classified as late-onset as they were expressed $72 \mathrm{~h}$ after exposure. Among these genes, 6 genes were time and dose responsive and validated further using alternate technology. These transcripts were upregulated and associated with biological processes related to immune function, organelle stability and cell signalling/communication. This panel of genes merits further validation to determine if they are strong candidate biomarkers indicative of $\alpha$-particle exposure.
\end{abstract}

\section{Introduction}

Counterterrorism and national security have become high priority issues worldwide. In spite of the magnitude of threats posed by radiological dispersal devices (RDDs), our capabilities for effectively responding to such a threat remain limited [1]. The majority of the isotopes suspected for use in RDDs are those emitting $\alpha$-particle radiation including Radium-226, Polonium-210, Americium-241, and Plutonium-238 [2]. These isotopes have a very long halflife, emitting their radiation slowly which results in very low continuous dose [2]. All are present in commercial products, in nuclear reactors, and radium-226 occurring in nature. It has been estimated in a simulated RDD scenario using Amercium-241, that of the exposed population, 35\% will receive a dose of between 0.05 and $5 \mathrm{~Sv}$ of radiation $[3,4]$. In a real radiological/nuclear event, the ability to accurately and rapidly estimate the level of exposure to the people at risk is paramount to successful medical intervention. As such, high-throughput methods of radiation detection are desirable. To date, the majority of the radiation detection capabilities have relied on cytogenetic analysis of blood from the exposed individual. However these techniques are time consuming and limited by low throughput. With the widespread use of genomics and proteomics technology in biomarker discovery, the development of a biological assessment tool based on gene markers may prove to be more viable, especially with $\alpha$-particle radiation due to its high damaging capacity.

It has been estimated that the damage received from one alpha particle is $\sim 20$ times more damaging than Xrays. Alpha particles have a high linear energy transfer (LET) which are typically $160 \mathrm{keV} \cdot \mu \mathrm{m}^{-1}$ for $2.5 \mathrm{MeV} \alpha$ particles in comparison to $2.0 \mathrm{keV} \cdot \mu \mathrm{m}^{-1}$ for $\mathrm{X}$-rays [5]. High LET $\alpha$-particles create very dense ionizing tracks as they traverse a medium. Therefore, they produce more significant biological effects when compared to equal absorbed doses from low LET radiation, which are more sparsely ionizing $[5,6]$. If ingested or inhaled, radionuclides which emit $\alpha$ particles can cause significant damage to sensitive cells and internal human tissue [7]. Alpha particle radiation results in adverse biological effects that can lead to systemic effects and 
the expression of a wide spectrum of biomolecules (genes, proteins, lipids, and peptides) that may be differentially modulated and therefore can serve as potential biomarkers. Indeed, the naturally occurring $\alpha$-particle emitter radon gas $\left({ }^{222} \mathrm{Rn}\right)$ has been shown to cause effects and perturbations of the normal state as exemplified by the induction of lung cancer in uranium miners, and further studies with animals have also shown a strong correlation between the exposure of ${ }^{222} \mathrm{Rn}$ and the incidence of lung cancer $[8,9]$. When inhaled, ${ }^{222} \mathrm{Rn}$ gas penetrates into the alveoli, where gas exchange takes place between the lungs and the blood. In general, this can lead to cascade of events that can cause damage to the sensitive cells lining the lungs and to the surrounding nucleated blood cells [10]. This may result in severe cytogenetic damage as a result of multiple ionizations within the DNA structure [11]. A number of in vitro and in vivo studies have shown that $\alpha$-particle exposure can lead to mutagenic changes including large deletions, frameshifts, and base-change mutations (reviewed 12).

Relatively few studies have examined global gene expression changes following exposure to $\alpha$-particle radiation [1214]. This study design was chosen with the overarching goal of identifying gene markers of $\alpha$-particle radiation exposure at dose levels that may have relevance to moderate dose whole body exposures. Thus, we sought to explore the merit of genomic profiling strategies in biomarker discovery following in vitro exposure of human monocytic cells to $\alpha$ particle radiation. The screening of 40,000 genes in this blood monocytic cell line will allow for the identification of a panel of markers that can be used further for screening in vivo and in occupational cohorts.

\section{Materials and Methods}

2.1. Cell Culture. A human monocytic cell line (THP-1) cultured from the blood of a male with acute monocytic leukemia was obtained from American Type Culture Collection (ATCC, Manassas, VA, USA). THP-1 cells were maintained in a humidified incubator $\left(37^{\circ} \mathrm{C}, 5 \% \mathrm{CO}_{2} / 95 \%\right.$ air) in $75 \mathrm{~cm}^{2}$ tissue culture flasks (Costar, Cambridge, MA, USA). The cells were grown to confluence for 2-3 days in Royal Park Medical Institute-1640 (RPMI-1640) (Invitrogen Canada, Burlington, ON, Canada) medium, containing 10\% fetal bovine serum (FBS) (Sigma-Aldrich Canada, Oakville, ON, Canada). A total of $1.0 \times 10^{6}$ cells were seeded into $5 \mathrm{~mL}$ of culture media containing 100 units $/ \mathrm{mL}$ of penicillin and $100 \mu \mathrm{g} / \mathrm{mL}$ of streptomycin (Invitrogen Canada Inc.). The cells were exposed to $\alpha$-particle radiation at doses ranging from 0.0 (control) to $1.5 \mathrm{~Gy}$, using ${ }^{241}$ Americium $\left({ }^{241} \mathrm{Am}\right)$ electroplated discs (Eckert and Ziegler Isotope Products Ltd., Valencia, CA, USA) having an activity level of $66.0 \mathrm{kBq} \pm 3 \%$ (dose rate of $0.98 \pm 0.01 \mathrm{~Gy} / \mathrm{h}$, LET of $127.4 \pm 0.4 \mathrm{keV} / \mu \mathrm{m})$. The absorbed dose of $\alpha$-radiation to which cells were exposed was calculated using the GEANT4 v.9.1 Monte Carlo toolkit [15]. For the $\alpha$-particle exposures, cells were cultured in thin Mylar-based plastic dishes (MDs) (Chemplex Industries, Palm City, FL, USA), which allowed penetration of the $\alpha$-particles. Cell viability and apoptotic data are presented in a previous manuscript [16].

2.2. RNA Extraction. Twenty-four hours and three days following exposure to $\alpha$-particle radiation or negative control conditions, $5 \mathrm{~mL}$ of cell culture were transferred to $15 \mathrm{~mL}$ Falcon centrifuge tubes (Invitrogen, Canada) and centrifuged at $200 \times \mathrm{g}$ for $5 \mathrm{~min}$ to pellet the cells. The supernatant was decanted, and the pelleted cells were resuspended in $350 \mu \mathrm{L}$ of Buffer RLT containing $1 \% \beta$-Mercaptoethanol (Qiagen's RNeasy Mini kit; Qiagen Inc., Mississauga, ON) and then frozen at $-80^{\circ} \mathrm{C}$ until processed. Frozen THP1 cells were thawed on ice and mixed well by pipetting. The lysate was transferred directly onto a QIAshredder spin column (Qiagen Inc.), placed in a $2 \mathrm{~mL}$ collection tube and centrifuged for $2 \mathrm{~min}$ at $\sim 12,000 \mathrm{~g}$. A volume of $350 \mu \mathrm{L}$ of $70 \%$ ethanol was added. Total RNA was then extracted using the RNeasy Mini kit according to the manufacturer's instructions (Qiagen Inc.), with the addition of Qiagen's On-Column RNase-free DNase (Qiagen Inc.) to eliminate any remaining DNA contamination. All total RNA sample concentrations and RNA quality were determined using both an Agilent 2100 Bioanalyzer and RNA Nanochips (Agilent Technologies Canada Inc., Mississauga, ON) and spectrophotometrically using a Nanodrop (Fisher Scientific) (OD ratio of A260:A280). All extracted RNA samples were determined to be of good quality (RNA Integrity Number = 10) with minimal degradation and stored at $-80^{\circ} \mathrm{C}$ until further analysis. Samples with an RIN value of greater than or equal to 8.0 were deemed to be acceptable for analysis. An input of $200 \mathrm{ng}$ of total RNA was used for whole genome analysis following the Illumina(r) Whole Genome Expression Profiling Assay Guide (11317302 Rev. A). Samples were hybridized on Illumina human-12 v2 RNA BeadChips. BeadChips were imaged and quantified with the Illumina iScan scanner, and data was processed with Illumina GenomeStudio v2010.2.

2.3. Statistical Analysis. Data preprocessing was done within GenomeStudio, where the intensities were averaged per probe/gene. Normalization of dataset was conducted in GeneSpring (version GX 11.5). Intensities were normalized to the 25th percentile. Intensities were $\log 2$ transformed, and a two-tailed $t$-test was performed. The variance was not assumed to be the same between the groups. Multiple testing using Benjamini and Hochberg false discovery correction was applied to the $P$ values in order to obtain robust responding gene targets.

2.4. Quantitative Real Time-Polymerase Chain Reaction ( $q R T$ $P C R$ ). Selected genes identified by microarray analysis displaying statistical significance, with fold changes of 2 or higher and for which primers were validated, were further assessed by qRT-PCR. Total RNA (100 ng) isolated from cells was reverse transcribed into complementary DNA using the RT2 First Strand Kit (SABiosciences Corp., Frederick, Maryland, USA). Gene profiling was performed according to the manufacturer instructions using custom RT2-profiler 
PCR arrays (SABiosciences Corp.). Reactions were prepared in 96-well plates and performed in duplicate in a spectrofluorometric thermal cycler (Biorad iCycler; Hercules, CA). The relative expression of each gene was determined by using the comparative threshold $(\mathrm{Ct})$ method [13]. Analysis of qRT-PCR expression profiles and statistical analysis of data were performed using the superarray biosciences web portal for data analysis of their products. (SABiosciences http://www.sabiosciences.com/pcr/arrayanalysis.php).

2.5. Pathway Analysis. Significantly expressed genes obtained from the exposure of human monocytic cells to $\alpha$-particle radiation were used for pathway analysis. Gene lists for the dose-dependent genes for both time points were uploaded into data analysis software (Ingenuity Pathway Analysis (IPA), version 7.5; Ingenuity Systems, CA) (IPA, 2005) and used for core analysis with the following settings: Reference Set $=$ Ingenuity's Knowledge Base (genes only) $[17,18]$. The same lists were also uploaded as filtered datasets for use in overlaying expression values with the following additional settings: fold-change cutoff $=1.0, P$ value cutoff $=$ 0.05 , focus on up- and downregulated identifiers, resolve duplicates $=$ maximum fold change, color nodes by fold change. Core comparison analysis was also run to show the differences in top functions and canonical pathways among the different lists. Functional analysis results were obtained after the analysis was complete. The top high-level and corresponding low-level functions were studied to determine the involved genes and whether those genes increase or decrease the specific function, to make conclusions about the mechanisms in flux after exposure to $\alpha$-particle radiation. Canonical pathway results were obtained after the analysis was complete. Canonical pathway results were customized to display the Benjamini-Hochberg multiple testing correction $P$ value to assist in omitting false-positive results from the analysis. The threshold used was $P$ value $=0.05$ (5\% false positive rate). Canonical pathways that had a $P$ value of 0.05 or less were further studied to determine the genes that were regulated from these datasets, and how these genes specifically affect the canonical pathway. Networks were used to further corroborate the functional analysis and canonical pathway results and to provide insight into any regulatory mechanisms. Networks were also used to view the molecular connections between the genes of interest to determine if they collectively share common biological functions when working together.

\section{Results}

3.1. Gene Profiling Twenty-Four Hours after Exposure. To mine for reliable genes, all differentially expressed genes were filtered on flagged spots that were of poor quality, a 1.5-fold change cut-off and a $P$ value $<0.05$. A total of 41 genes were shown to be expressed solely at the low dose of radiation (0.5 Gy, $P<0.05,|\mathrm{FC}|>1.5$ ) (data not shown), and all of these transcripts were upregulated. A total of 21 genes $(P<$ $0.05,|\mathrm{FC}|>1.5)$ were exclusively expressed at the medium (1.0 Gy) and high (1.5 Gy) dose, and all of these genes were
TABLE 1: Expression profile of genes that were shown to be statistically significant (a) $24 \mathrm{~h}$ and (b) $72 \mathrm{~h}$ following alpha-particle irradiation at all doses using microarray analysis. Statistics based on an $n=5$ biological replicates.

(a) $24 \mathrm{~h}$

\begin{tabular}{|c|c|c|c|}
\hline & $0.5 \mathrm{~Gy}$ & $1.0 \mathrm{~Gy}$ & $1.5 \mathrm{~Gy}$ \\
\hline Number of Transcripts & 38 & 84 & 163 \\
\hline $\begin{array}{l}\text { Common Amongst All Doses } \\
(\%)\end{array}$ & $15(39)$ & $15(18)$ & $15(9)$ \\
\hline Exclusive (\%) & $13(34)$ & $10(12)$ & $87(53)$ \\
\hline Upregulated (\%) & $38(100)$ & $81(96)$ & $147(30)$ \\
\hline $\begin{array}{l}\text { Common Amongst All Doses } \\
(\%)\end{array}$ & $15(39)$ & $15(18)$ & $15(51)$ \\
\hline Exclusive (\%) & $13(34)$ & $10(5)$ & $74(18)$ \\
\hline Downregulated (\%) & N/A (0) & $3(4)$ & $16(10)$ \\
\hline $\begin{array}{l}\text { Common Amongst All Doses } \\
(\%)\end{array}$ & N/A & $3(100)$ & $3(19)$ \\
\hline Exclusive (\%) & N/A & $0(0)$ & $13(81)$ \\
\hline
\end{tabular}

(b) $72 \mathrm{~h}$

\begin{tabular}{lccc}
\hline & $0.5 \mathrm{~Gy}$ & $1.0 \mathrm{~Gy}$ & $1.5 \mathrm{~Gy}$ \\
\hline $\begin{array}{l}\text { Number of Transcripts } \\
\begin{array}{l}\text { Common Amongst All Doses } \\
(\%)\end{array}\end{array}$ & $\mathbf{1 4 3}$ & $\mathbf{1 5 2}$ & $\mathbf{1 9 0}$ \\
$\begin{array}{l}\text { Exclusive (\%) } \\
\text { Upregulated (\%) }\end{array}$ & $\mathbf{4 7}(31)$ & $\mathbf{4 7}(25)$ \\
$\begin{array}{l}\text { Common Amongst All Doses } \\
(\%)\end{array}$ & $\mathbf{1 1 0 ( 7 7 )}$ & $\mathbf{2 4}(16)$ & $\mathbf{5 0}(26)$ \\
$\begin{array}{l}\text { Exclusive (\%) } \\
\text { Downregulated (\%) }\end{array}$ & $15(63)$ & $15(8)$ \\
$\begin{array}{l}\text { Common Amongst All Doses } \\
(\%)\end{array}$ & $\mathbf{3 3}(23)$ & $\mathbf{1 2 8}(84)$ & $\mathbf{1 4 0}(74)$ \\
Exclusive (\%) & $32(25)$ & $32(23)$ \\
\hline
\end{tabular}

upregulated (data not shown). Only 16 genes were shown to be dose-responsive (Table 1), and expression of these genes was observed to be higher relative to unexposed cells. Strong expressors with high fold changes were observed for transcripts TRIB3, SPP1, and CD14 (>3 fold at the highest dose).

3.2. Gene Profiling Three Days Following Exposure. As previous work from our laboratory [16] has shown an apoptotic response to occur 4 days subsequent to $\alpha$-particle exposure, in this study gene expression changes were monitored at three days after exposure, before cells proceeded to undergo apoptosis. Significantly more genes were differentially expressed at this time point in comparison to the $24 \mathrm{~h}$ time point. Similar to the $24 \mathrm{~h}$ time point all genes listed in the Tables are statistically significant and with fold changes $>1.5$. At the low dose of radiation $(0.5 \mathrm{~Gy})$ a total of 62 genes were differentially expressed $(P<0.05,|\mathrm{FC}|>1.5), 55 \%$ of these genes were upregulated, and $45 \%$ were downregulated (data not shown). At the low and medium dose of radiation, a total of 50 genes were differentially expressed and 33 of 


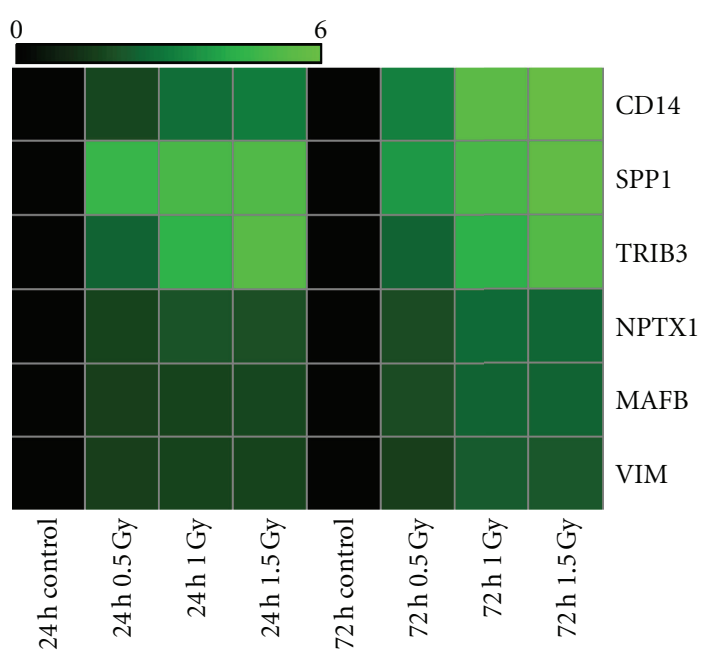

FIGURE 1: Heat map of dose- and time- responsive genes and corresponding fold changes from the microarray data. These genes were statistically significant $(P<0.05)$ at all doses and time points tested on an $n=5$ biological replicates.

these were upregulated and 17 were downregulated (data not shown). A total of 48 genes were expressed at all three doses (Table 2). Fold changes for these genes at the highest dose of radiation tested ranged from 5 -fold to -2.5 -fold. High expressors included CD14, SPP1, TRIB3; these genes were also shown to be expressed at $24 \mathrm{~h}$ after $\alpha$-particle exposure. Genes which were highly downregulated included INSIG1, KIT, SC4MOL, and SCD.

3.3. Dose- and Time-Responsive Genes. A total of 6 genes that were observed to be expressed at the $24 \mathrm{~h}$ time point were also shown to respond 3 days following $\alpha$-particle exposure (Table 3 ). These 6 genes may be highly radiation-specific and can be classified as dose- and time-responsive genes. All six of these genes were significantly upregulated. Three of these transcripts had expression levels of 5 fold or higher 3 days after exposure the genes include TRIB3, CD14, and SPP1. The 6 genes that exhibited time- and dose-dependant trends were further used to create a heat map analysis of all treatment groups (Figure 1). The figure further highlights the linear dose and time-response trends exhibited by the majority of these genes.

3.4. $q R T-P C R$ Gene Validation. For a selected few of the dose-time responsive genes and transcripts that were expressed at all doses at the 3 day time-point, qRT-PCR validation was performed. As shown in Table 4, all genes that exhibited a significant dose- and time-response were also observed to exhibit a similar trend using qRT-PCR. A comparable pattern of expression was also observed for the genes (INSIG1, KIT, S100P, ORM1) that were dose-responsive but not time-responsive using the two methodologies. Overall, these results show analogous responses between the two technologies.
3.5. Pathway Analysis. The dose-responsive genes expressed at $24 \mathrm{~h}$ and $72 \mathrm{~h}$ were used to conduct pathway analysis of the gene sets. Sixteen dose-responsive genes that were differentially expressed at the $24 \mathrm{~h}$ time point were inputted into the IPA analysis tool; the results are summarized in Table 5. The top canonical pathways for these gene sets included toll-like receptor signaling and MIF regulation of innate immunity. Only one network obtained a high score and it was associated with carbohydrate/lipid metabolism and small molecule biochemistry. The biofunctions of these genes in relation to disease and disorders were respiratory disease, genetic disorder, and inflammatory disease. Molecular and cellular functions included cell-cell signaling and interaction, cellular development, and cellular growth and proliferation. The physiological functions were in relation to tissue development and immune cell trafficking and nervous system development and function. The top genes associated with these pathways were SPP1, TRIB3, VCAN, CD14, ATF5, and $K C N G 1$; all were upregulated in expression following exposure to $\alpha$-particles.

Forty-eight genes that were expressed at the $72 \mathrm{~h}$ time point were inputted into the IPA analysis tool. The data showed similar responding pattern of effects to the genes obtained $24 \mathrm{~h}$ after $\alpha$-particle exposure (Table 6). The top networks associated with this gene set included lipid metabolism, cell-to-cell signaling interaction, cell death, and developmental disorder. The top biofunctions in relation to diseases and disorders were cancer, respiratory disease, and inflammatory response. Molecular and cellular functions of these genes were in relation to lipid metabolism, molecular transport, and cellular movement. In terms of physiological system development and function the top biofunctions of the genes were in relation to haematological system development and function, immune cell trafficking, lymphoid tissue structure and development. The top canonical pathways associated with these genes were IL-6 signaling, p53 signaling, and airway pathology in chronic obstructive pulmonary disease. The genes associated with these pathways included SPP1, CD14, TRIB3, S100P, S100A9, LYZ, IL8, PLIN2, S100A8, and INSIG1. All were upregulated in expression with the exception of INSIG1 which was downregulated by $\sim 2$-fold following $\alpha$-particle irradiation.

\section{Discussion}

In this study the biological effects of $\alpha$-particle radiation at the genome level were monitored at two time points and three doses with the goal to identify potential gene targets that are modulated with the radiation exposure. These changes were monitored in a human monocytic cell line which may be more relevant to biomarker discovery. This cell line serves as a good model for use in an initial screening to identify potential biomarkers of $\alpha$-particle radiation exposure. However, further studies would be required to confirm the validity of these markers using in vivo studies and investigations based on using occupational cohorts.

The results from this study show that $\alpha$-particles elicit strong responses at the transcript level in THP-1 cells, and 
TABLE 2: Expression profiles of genes that were shown to be statistically significant $72 \mathrm{~h}$ after alpha-particle irradiation at all doses. Statistics based on an $n=5$ biological replicates.

\begin{tabular}{|c|c|c|c|c|c|c|c|}
\hline Accession no. & Symbol & FC-D1 & $\mathrm{Pv}$ & FC-D2 & $\mathrm{Pv}$ & FC-D3 & $\mathrm{Pv}$ \\
\hline NM_001040021.1 & CD14 & 3.15 & 0.00 & 5.50 & 0.00 & 5.89 & 0.00 \\
\hline NM_000582.2 & SPP1 & 3.72 & 0.00 & 4.98 & 0.00 & 5.68 & 0.04 \\
\hline NM_021158.3 & TRIB3 & 2.43 & 0.00 & 4.32 & 0.00 & 5.34 & 0.00 \\
\hline NM_000607.1 & ORM1 & 2.49 & 0.00 & 3.62 & 0.00 & 3.67 & 0.00 \\
\hline NM_005980.2 & S100P & 2.28 & 0.00 & 3.25 & 0.00 & 3.44 & 0.00 \\
\hline NM_002965.2 & S100A9 & 2.13 & 0.00 & 2.43 & 0.00 & 2.48 & 0.00 \\
\hline NM_002522.2 & NPTX1 & 1.82 & 0.00 & 2.57 & 0.00 & 2.48 & 0.00 \\
\hline NM_006216.2 & SERPINE2 & 1.75 & 0.00 & 2.51 & 0.00 & 2.44 & 0.00 \\
\hline NM_001122.2 & ADFP & 1.88 & 0.02 & 2.29 & 0.00 & 2.43 & 0.00 \\
\hline NM_005461.3 & MAFB & 1.86 & 0.01 & 2.36 & 0.00 & 2.41 & 0.00 \\
\hline NM_001995.2 & ACSL1 & 1.55 & 0.00 & 2.34 & 0.00 & 2.34 & 0.00 \\
\hline NM_001375.2 & DNASE2 & 1.66 & 0.01 & 2.05 & 0.00 & 2.22 & 0.00 \\
\hline NM_002964.3 & S100A8 & 1.87 & 0.00 & 2.19 & 0.00 & 2.21 & 0.00 \\
\hline NM_000239.1 & LYZ & 2.08 & 0.00 & 2.26 & 0.00 & 2.19 & 0.00 \\
\hline NM_015869.4 & PPARG & 1.68 & 0.00 & 2.13 & 0.00 & 2.17 & 0.00 \\
\hline NM_019058.2 & DDIT4 & 1.57 & 0.00 & 2.15 & 0.00 & 2.15 & 0.00 \\
\hline NM_000104.2 & CYP1B1 & 1.82 & 0.00 & 2.15 & 0.00 & 2.13 & 0.00 \\
\hline NM_003380.2 & VIM & 1.56 & 0.00 & 2.20 & 0.00 & 2.10 & 0.00 \\
\hline NM_000584.2 & IL8 & 2.01 & 0.01 & 2.07 & 0.00 & 2.07 & 0.01 \\
\hline NM_000632.3 & ITGAM & 1.83 & 0.00 & 2.07 & 0.00 & 2.06 & 0.00 \\
\hline NM_006366.2 & CAP2 & 1.51 & 0.00 & 1.92 & 0.00 & 2.03 & 0.00 \\
\hline NM_002928.2 & RGS16 & 1.54 & 0.00 & 1.66 & 0.00 & 1.98 & 0.00 \\
\hline NM_003376.4 & VEGFA & 1.54 & 0.00 & 2.03 & 0.00 & 1.97 & 0.00 \\
\hline NM_003916.3 & AP1S2 & 1.60 & 0.00 & 2.01 & 0.00 & 1.97 & 0.00 \\
\hline NM_004811.1 & LPXN & 1.50 & 0.00 & 2.18 & 0.00 & 1.94 & 0.00 \\
\hline NM_174918.2 & C19orf59 & 1.55 & 0.00 & 2.12 & 0.00 & 1.92 & 0.00 \\
\hline NM_013363.2 & PCOLCE2 & 1.68 & 0.00 & 1.96 & 0.00 & 1.90 & 0.00 \\
\hline NM_000889.1 & ITGB7 & 1.68 & 0.00 & 1.91 & 0.00 & 1.89 & 0.00 \\
\hline NM_001629.2 & ALOX5AP & 1.57 & 0.00 & 1.98 & 0.00 & 1.81 & 0.00 \\
\hline NR_002203.1 & FTHL8 & 1.51 & 0.03 & 1.67 & 0.00 & 1.67 & 0.00 \\
\hline NM_018004.1 & TMEM45A & 1.53 & 0.01 & 1.92 & 0.00 & 1.60 & 0.00 \\
\hline NM_000265.4 & NCF1 & 1.53 & 0.01 & 1.55 & 0.01 & 1.55 & 0.00 \\
\hline NM_003583.2 & DYRK2 & 0.57 & 0.02 & 0.64 & 0.01 & 0.63 & 0.01 \\
\hline NM_152764.1 & C16orf73 & 0.64 & 0.00 & 0.65 & 0.00 & 0.62 & 0.00 \\
\hline NM_001821.3 & CHML & 0.54 & 0.01 & 0.61 & 0.00 & 0.61 & 0.00 \\
\hline NM_002130.6 & HMGCS1 & 0.54 & 0.01 & 0.56 & 0.00 & 0.61 & 0.00 \\
\hline NM_005640.1 & TAF4B & 0.56 & 0.01 & 0.66 & 0.01 & 0.61 & 0.03 \\
\hline NM_001005291.1 & SREBF1 & 0.61 & 0.01 & 0.62 & 0.00 & 0.59 & 0.00 \\
\hline NM_001093772.1 & KIT & 0.58 & 0.00 & 0.60 & 0.00 & 0.57 & 0.00 \\
\hline NM_000527.2 & LDLR & 0.60 & 0.03 & 0.59 & 0.00 & 0.56 & 0.00 \\
\hline NM_000820.1 & GAS6 & 0.62 & 0.02 & 0.64 & 0.00 & 0.54 & 0.00 \\
\hline NM_033445.2 & HIST3H2A & 0.48 & 0.02 & 0.58 & 0.04 & 0.54 & 0.02 \\
\hline NR_002771.1 & DLEU2L & 0.57 & 0.01 & 0.60 & 0.00 & 0.53 & 0.00 \\
\hline XR_001514.1 & DLEU2 & 0.64 & 0.01 & 0.60 & 0.00 & 0.51 & 0.00 \\
\hline NM_005063.4 & SCD & 0.56 & 0.01 & 0.57 & 0.00 & 0.49 & 0.00 \\
\hline NM_001017369.1 & SC4MOL & 0.54 & 0.01 & 0.53 & 0.01 & 0.48 & 0.00 \\
\hline NM_000222.1 & KIT & 0.50 & 0.01 & 0.53 & 0.00 & 0.42 & 0.00 \\
\hline NM_198336.1 & INSIG1 & 0.54 & 0.03 & 0.44 & 0.00 & 0.41 & 0.00 \\
\hline
\end{tabular}


TABLE 3: Expression profile of genes validated using qRT-PCR. Fold changes and associated $P$ values are indicated for both time points and all doses.

\begin{tabular}{|c|c|c|c|c|c|c|c|c|c|c|c|c|c|}
\hline \multirow{2}{*}{ Accession no. } & \multirow{2}{*}{ Symbol } & \multicolumn{4}{|c|}{$0.5 \mathrm{~Gy}$} & \multicolumn{4}{|c|}{$1.0 \mathrm{~Gy}$} & \multicolumn{4}{|c|}{$1.5 \mathrm{~Gy}$} \\
\hline & & FC-T1 & $\mathrm{Pv}$ & FC-T2 & $\mathrm{Pv}$ & FC-T1 & $\mathrm{Pv}$ & FC-T2 & $\mathrm{Pv}$ & FC-T1 & $\mathrm{Pv}$ & FC-T2 & $\mathrm{Pv}$ \\
\hline NM_000582 & SPP1 & 10.865 & $1.2 E-05$ & 16.3775 & 0.0164 & 15.48 & $4 E-04$ & 21.56 & 0.0456 & 15.18 & $3 E-06$ & 22.026 & 0.163 \\
\hline NM_000591 & $\mathrm{CD} 14$ & 2.349 & 0.0011 & 7.8024 & 0 & 4.927 & 0.001 & 10.66 & $8 E-06$ & 6.215 & $2 E-04$ & 11.534 & 0.01 \\
\hline NM_002522 & NPTX1 & 1.485 & 0.07025 & 3.1824 & $4 E-05$ & 2.39 & $6 E-04$ & 3.523 & $2 E-05$ & 2.599 & $8 E-05$ & 3.2643 & 0.008 \\
\hline NM_003380 & VIM & 1.2647 & 0.30111 & 2.3705 & 0.0161 & 1.248 & 0.271 & 2.965 & 0.0008 & 1.622 & 0.028 & 3.1475 & 0.004 \\
\hline NM_005461 & MAFB & 1.4789 & 0.15033 & 4.4038 & 0.0001 & 2.139 & 0.012 & 5.656 & $6 E-05$ & 2.968 & $6 E-04$ & 4.9452 & 0.017 \\
\hline NM_021158 & TRIB3 & 2.0386 & 0.01668 & 3.2229 & 0.0002 & 5.729 & $3 E-04$ & 5.373 & 0.0003 & 6.746 & $4 E-04$ & 5.7073 & $3 E-04$ \\
\hline NM_005542 & INSIG1 & -1.58 & 0.00271 & -2.01 & 0.0228 & -1.36 & 0.013 & -2.56 & 0.001 & -1.75 & 0.002 & -2.89 & $6 E-04$ \\
\hline NM_000222 & KIT & -1.18 & 0.20533 & -2.515 & 0.0101 & -1.09 & 0.411 & -3.22 & 0.0014 & -1.49 & 0.014 & -3.35 & 0.001 \\
\hline NM_005980 & S100P & 0.9565 & 0.66173 & 3.9682 & $4 E-06$ & 1.371 & 0.067 & 4.48 & $2 E-06$ & 1.632 & 0.002 & 4.5418 & $2 E-05$ \\
\hline NM_000607 & ORM1 & 1.0251 & 0.83691 & 4.5517 & 0.0003 & 1.406 & 0.048 & 6.452 & 0.0003 & 1.638 & 0.02 & 6.4402 & $5 E-04$ \\
\hline
\end{tabular}

TABLE 4: Expression profiles of genes that were observed to be dose- and time-responsive using microarray technology.

\begin{tabular}{lcccccccccccc}
\hline \multirow{2}{*}{ Symbol } & \multicolumn{9}{c}{$0.5 \mathrm{~Gy}$} & \multicolumn{4}{c}{$1.0 \mathrm{~Gy}$} & \multicolumn{4}{c}{$1.5 \mathrm{~Gy}$} \\
& FC-T1 & Pv & FC-T2 & Pv & FC-T1 & Pv & FC-T2 & Pv & FC-T1 & Pv & FC-T2 & Pv \\
\hline CD14 & 1.77 & 0.00 & 3.15 & 0.00 & 2.63 & 0.00 & 5.50 & 0.00 & 3.08 & 0.00 & 5.89 & 0.00 \\
MAFB & 1.59 & 0.00 & 1.86 & 0.01 & 1.63 & 0.00 & 2.36 & 0.00 & 1.77 & 0.00 & 2.41 & 0.00 \\
NPTX1 & 1.62 & 0.00 & 1.82 & 0.00 & 1.98 & 0.00 & 2.57 & 0.00 & 1.90 & 0.00 & 2.48 & 0.00 \\
SPP1 & 4.61 & 0.00 & 3.72 & 0.00 & 5.05 & 0.00 & 4.98 & 0.00 & 5.17 & 0.00 & 5.68 & 0.04 \\
TRIB3 & 2.40 & 0.00 & 2.43 & 0.00 & 4.46 & 0.00 & 4.32 & 0.00 & 5.39 & 0.00 & 5.34 & 0.00 \\
VIM & 1.56 & 0.00 & 1.56 & 0.00 & 1.62 & 0.00 & 2.20 & 0.00 & 1.62 & 0.00 & 2.10 & 0.00 \\
\hline
\end{tabular}

TABLE 5: Canonical functions and networks of dose-responsive genes that were differentially expressed $24 \mathrm{~h}$ after irradiation

\begin{tabular}{lcc}
\hline Category & Score & $P$ value \\
\hline $\begin{array}{l}\text { Networks } \\
\quad \text { Carbohydrate Metabolism, Lipid }\end{array}$ & & \\
$\quad$ Metabolism, Small Molecule Biochemistry & 21 & N/A \\
Diseases and Disorders & & \\
$\quad$ Genetic Disorder & N/A & $4.45 E-02$ \\
$\quad$ Inflammatory Response & N/A & $3.85 E-02$ \\
$\quad$ Respiratory Disease & N/A & $4.40 E-02$ \\
Molecular and Cellular Functions & & \\
$\quad$ Cell-To-Cell Signalling and Interaction & N/A & $4.60 E-02$ \\
$\quad$ Cellular Development & N/A & $4.80 E-02$ \\
$\quad$ Cellular Growth and Proliferation & N/A & $3.66 E-02$ \\
Physiological System Development and & & \\
Function & & \\
$\quad \begin{array}{l}\text { Tissue Development } \\
\text { Haematological System Development } \\
\text { and Function }\end{array}$ & N/A & $4.25 E-02$ \\
$\quad$ Immune Cell Trafficking & N/A & $4.80 E-02$ \\
Top Canonical Pathways & N/A & $4.60 E-02$ \\
$\quad \begin{array}{l}\text { MIF Regulation of Innate Immunity } \\
\text { Toll-like Receptor Signalling }\end{array}$ & N/A & $2.05 E-02$ \\
\hline & N/A & $2.50 E-02$ \\
\hline
\end{tabular}

these responses vary with time point and dose of radiation. Although gene modulations were obtained independently at each of the doses tested, only those responses that were elicited at all doses may be important candidate biomarkers that would require further validation. Gene expression changes were monitored at $24 \mathrm{~h}$ and $72 \mathrm{~h}$ following exposure. Of the $\sim 48,000$ transcripts that were screened for expression, only 16 genes were differentially expressed relative to untreated samples at the $24 \mathrm{~h}$ time point at all three doses tested. Three days following $\alpha$-particle exposure a greater number of genes were expressed, with a total of 48 genes showing dose-responsive trends. Analysis of theses gene sets showed networks related to cell-to-cell signaling and interaction, molecular transport, lipid/carbohydrate, organism injury, and abnormalities. The disease and disorders related to these genes were respiratory disease, cancer, and inflammatory disease. Top toxicological pathways in relation to disease include airway pathology in chronic obstructive pulmonary disease. Among these 48 genes, only 6 were also present $24 \mathrm{~h}$ after exposure. It is these six genes that may warrant further studies. Gene ontology analysis of these six genes (TRIB3, CD14, VCAN, SPP1, NPTX1, $M A F B, V I M)$ suggests that they are associated with functions related to immune function, organelle stability, and cell signalling/communication and pathways associated with p53 signaling and IL-6 signaling (Table 7). Although not within the scope of this study, further studies are required to determine the specificity of this response to this radiation type in comparison to other radiation types. 
Table 6: Canonical Functions and networks associated with the dose responsive genes that were differentially expressed $72 \mathrm{~h}$ after irradiation.

\begin{tabular}{|c|c|c|}
\hline Category & Score & $P$ value \\
\hline \multicolumn{3}{|l|}{ Networks } \\
\hline $\begin{array}{l}\text { Lipid Metabolism, Molecular } \\
\text { Transport, Small Molecule } \\
\text { Biochemistry }\end{array}$ & 36 & $\mathrm{~N} / \mathrm{A}$ \\
\hline $\begin{array}{l}\text { Carbohydrate Metabolism, } \\
\text { Cell-To-Cell Signalling and } \\
\text { Interaction, Cell Death }\end{array}$ & 14 & $\mathrm{~N} / \mathrm{A}$ \\
\hline $\begin{array}{l}\text { Developmental Disorder, } \\
\text { Organism Injury and Abnormalities, } \\
\text { Infectious Disease }\end{array}$ & 8 & $\mathrm{~N} / \mathrm{A}$ \\
\hline \multicolumn{3}{|l|}{ Diseases and Disorders } \\
\hline Cancer & N/A & $3.39 E-03$ \\
\hline Haematological Disease & N/A & $3.39 E-03$ \\
\hline Genetic Disorder & N/A & $3.39 E-03$ \\
\hline Inflammatory Response & N/A & $3.39 E-03$ \\
\hline Respiratory Disease & N/A & $2.38 E-03$ \\
\hline \multicolumn{3}{|l|}{ Molecular and Cellular Functions } \\
\hline Lipid Metabolism & $\mathrm{N} / \mathrm{A}$ & $3.39 E-03$ \\
\hline Molecular Transport & N/A & $3.39 E-03$ \\
\hline Small Molecule Biochemistry & N/A & $3.39 E-03$ \\
\hline Cell Death & N/A & $3.39 E-03$ \\
\hline Cellular Movement & N/A & $3.39 E-03$ \\
\hline \multicolumn{3}{|l|}{$\begin{array}{l}\text { Physiological System Development and } \\
\text { Function }\end{array}$} \\
\hline $\begin{array}{l}\text { Haematological System } \\
\text { Development and Function }\end{array}$ & N/A & $3.39 E-03$ \\
\hline Immune Cell Trafficking & N/A & $3.28 E-03$ \\
\hline $\begin{array}{l}\text { Lymphoid Tissue Structure and } \\
\text { Development }\end{array}$ & N/A & $3.33 E-03$ \\
\hline Tissue Development & $\mathrm{N} / \mathrm{A}$ & $3.39 E-03$ \\
\hline \multicolumn{3}{|l|}{ Top Canonical Pathways } \\
\hline IL-6 Signalling & N/A & $1.09 E-02$ \\
\hline p53 Signalling & N/A & $1.14 E-02$ \\
\hline $\begin{array}{l}\text { Airway Pathology in Chronic } \\
\text { Obstructive Pulmonary Disease }\end{array}$ & N/A & $1.35 E-02$ \\
\hline
\end{tabular}

Studies on $\alpha$-particle exposure and gene expression changes are limited; however a few studies have obtained similar findings. A recent study examined gene expression changes in human peripheral blood lymphocytes from two patients exposed ex vivo to $6.78 \mathrm{MeV}$ mean energy alpha particles from extracellular ${ }^{211}$ At source [14]. Two hours after exposure, at doses ranging from 0.05 to $1.6 \mathrm{~Gy}$, eight genes displayed a sustained up- or downregulation (CD36, HSPA2, MS4A6A, NFIL3, IL1F9, IRX5, RASL11B, and SULT1B1). A comparison of these results with our study shows a very similar grouping of genes, despite the use of different exposure conditions, cells, and time points. Both of the studies have obtained genes associated within the interleukin family of signaling molecules, cell cycle/division
TABLE 7: The biological functions associated with the time- and dose-responsive genes as determined using Ingenuity Pathway Analysis software.

\begin{tabular}{|c|c|c|}
\hline $\begin{array}{l}\text { Accession } \\
\text { number }\end{array}$ & Gene & Function \\
\hline NM_001040021.1 & CD14 & $\begin{array}{l}\text { Immune function, cell immunity } \\
\text { differentiation }\end{array}$ \\
\hline NM_005461.3 & MAFB & Transcription factor, hematopoiesis, \\
\hline NM_002522.2 & NPTX1 & Neural pathways, immune function \\
\hline NM_000582.2 & SPP1 & Immune function, antiapoptosis, \\
\hline NM_021158.3 & TRIB3 & $\begin{array}{c}\text { NF-kappa B signalling, AKT } 1 \\
\text { signalling, apoptosis }\end{array}$ \\
\hline NM_003380.2 & VIM & $\begin{array}{c}\text { Cell resilience to mechanical stress, } \\
\text { organelle stability, }\end{array}$ \\
\hline
\end{tabular}

processes, proliferation, and differentiation. In line with this, Roudkenar et al. [12] investigated the effect of particles and lithium nuclei generated by boron neutron capture reaction on mouse liver epithelial and Kupffer cells. Of the 6000 genes that were examined, 68 showed differential expressions compared to the nonirradiated controls. Some of the genes that were differentially expressed were involved in cell cycle regulation, intracellular transport, and fatty acid metabolism. In another study Seidl et al. [19] exposed gastric cancer cells to $\alpha$-particle irradiation and monitored global changes in gene expression. The authors identified majority of the significantly upregulated genes to be related to signal transduction processes. Overall results from these studies show that similarities exist between investigations in terms of the functional classification of the differentially expressed transcripts. This is promising as the six time- and doseresponsive genes merit further investigation to assess their potential to be biomarkers.

In summary, this study showed that $\alpha$-particles exert modulations upon the transcriptional activity of human leukemic monocytic cells. These modulations varied with dose and time subsequent to exposure. A subset of genes were identified that were expressed at low-to-moderate doses of radiation in a time- and dose-dependant manner. These genes broadly fall into the family of immune/signaling molecules and could be reliable candidate biomarkers of $\alpha$ particle radiation exposure. Although this study has verified the use of genomic technology for biomarker discovery, further validation of these results required using in vivo modeling and in vitro monocyte isolation from individuals. Future studies will validate these responses over a wider dose ranges and using alternate radiation types.
Abbreviations
$\left({ }^{241} \mathrm{Am}\right):$ Americium
$\left({ }^{222} \mathrm{Rn}\right)$ : Radon
$\left({ }^{226} \mathrm{Ra}\right)$ : Radium
$\left({ }^{210} \mathrm{Po}\right)$ : Polonium
(MD): $\quad$ Mylar Based plastic dishes
(FBS): Fetal bovine serum 
(TBS): $\quad$ Triphosphate buffered saline

(TST): $\quad$ TBS serum triton

(PBS): $\quad$ Phosphate buffered saline

$(\alpha)$ : Alpha

(MD): $\quad$ Mylar dish

(RPMI): Royal park medical institute

(ANOVA): Analysis of variance

(qRT-PCR): Quantitative real-time polymerase chain reaction

(Ct): $\quad$ Compartive threshold

(FC): $\quad$ Fold change

(RDDs): Radiological Dispersal Devices

(LET): $\quad$ Linear Energy Transfer

(IPA): $\quad$ Ingenuity Pathway Analysis.

\section{Conflict of Interests}

The authors declare no conflict of interests. The authors alone are responsible for the content and writing of the paper.

\section{Acknowledgment}

This work was supported by the Health Canada Genomics Research and Development Initiative.

\section{References}

[1] ICRP, "Protecting people against radiation exposure in the event of a radiological attack," Annals of the ICRP, vol. 35, no. $1,2005$.

[2] C. Ferguson and W. Potter, The Four Faces of Nuclear Terrorism, Center for Nonproliferation Studies, Monterey, Calif, USA, 2004.

[3] R. Arutyunian, L. Bolshov, and O. Pavlovskiy, "Radiological terrorism: threat, priorities in prevention, and minimization of consequences," in Social and Psychological Effects of Radiological Terrorism, I. Khripunov, L. Bolshov, and D. Nikonov, Eds., pp. 25-46, IOS Press, Fairfax, Va, USA, 2007.

[4] H. Kelly, Statement to the Senate, Committee on Foreign Relations, 2002, http://www.fas.org/ssp/docs/kelly_testimony_ 030602.pdf.

[5] H. E. Johns and J. R. Cunningham, The Physics of Radiology, Charles C. Thomas, Springfield, Ill, USA, 4 edition, 1983.

[6] H. Cember, Introduction to Health Physics, McGraw-Hill, 3 edition, 1996.

[7] I. A. M. Al-Affan and A. K. M. M. haque, "Local energy deposited for alpha particles emitted from inhaled radon daughters," Physics in Medicine and Biology, vol. 34, no. 1, pp. 97-105, 1989.

[8] J. W. Stather, "Dosimetric and epidemiological approaches to assessing radon doses_-can the differences be reconciled?" Radiation Protection Dosimetry, vol. 112, no. 4, pp. 487-492, 2004.

[9] M. Al-Zoughool and D. Krewski, "Health effects of radon: a review of the literature," International Journal of Radiation Biology, vol. 85, no. 1, pp. 57-69, 2009.

[10] National Research Council, Health Effects of Exposure to Radon (BEIR VI), National Academy Press, Washington, DC, USA, 1999.
[11] D. T. Goodhead, "Initial events in the cellular effects of ionizing radiations: clustered damage in DNA," International Journal of Radiation Biology, vol. 65, no. 1, pp. 7-17, 1994.

[12] M. H. Roudkenar, L. Li, T. Baba et al., "Gene expression profiles in mouse liver cells after exposure to different types of radiation," Journal of Radiation Research, vol. 49, no. 1, pp. 29-40, 2008.

[13] E. I. Azzam, S. M. De Toledo, and J. B. Little, "Expression of CONNEXIN43 is highly sensitive to Ionizing radiation and other environmental stresses," Cancer Research, vol. 63, no. 21, pp. 7128-7135, 2003.

[14] A. Turtoi, I. Brown, M. Schläger, and F. H. A. Schneeweiss, "Gene expression profile of human lymphocytes exposed to 211 at $\alpha$ particles," Radiation Research, vol. 174, no. 2, pp. 125136, 2010.

[15] L. A. Beaton, T. A. Burn, T. J. Stocki, V. Chauhan, and R. C. Wilkins, "Development and characterization of an in vitro alpha radiation exposure system," Physics in Medicine and Biology, vol. 56, no. 12, pp. 3645-3658, 2011.

[16] V. Chauhan, M. Howland, J. Chen, B. Kutzner, and R. C. Wilkins, "Differential effects of alpha-particle radiation and $\mathrm{x}$-irradiation on genes associated with apoptosis," Radiology Research and Practice, vol. 2011, Article ID 679806, 9 pages, 2011.

[17] IPA Calculating and interpreting the p-values for functions, pathways, and lists in Ingenuity Pathways Analysis, Ingenuity Systems, 2009, http://www.ingenuity.com/.

[18] IPA Network Generation Algorithm, Ingenuity Systems, 2005, http://www.ingenuity.com/.

[19] C. Seidl, M. Port, C. Apostolidis et al., "Differential gene expression triggered by highly cytotoxic $\alpha$-emitter-immunoconjugates in gastric cancer cells," Investigational New Drugs, vol. 28 , no. 1, pp. 49-60, 2010. 

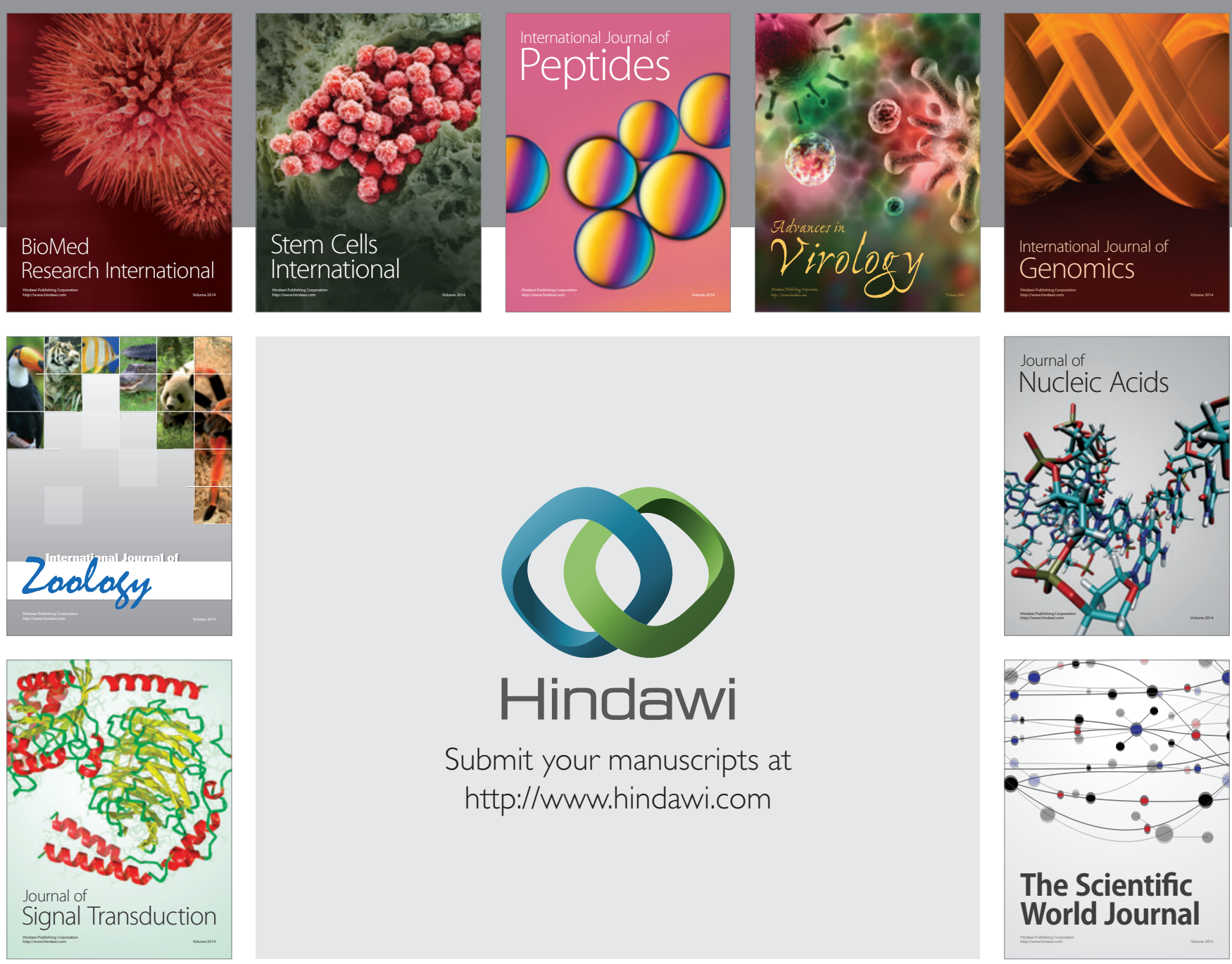

Submit your manuscripts at

http://www.hindawi.com
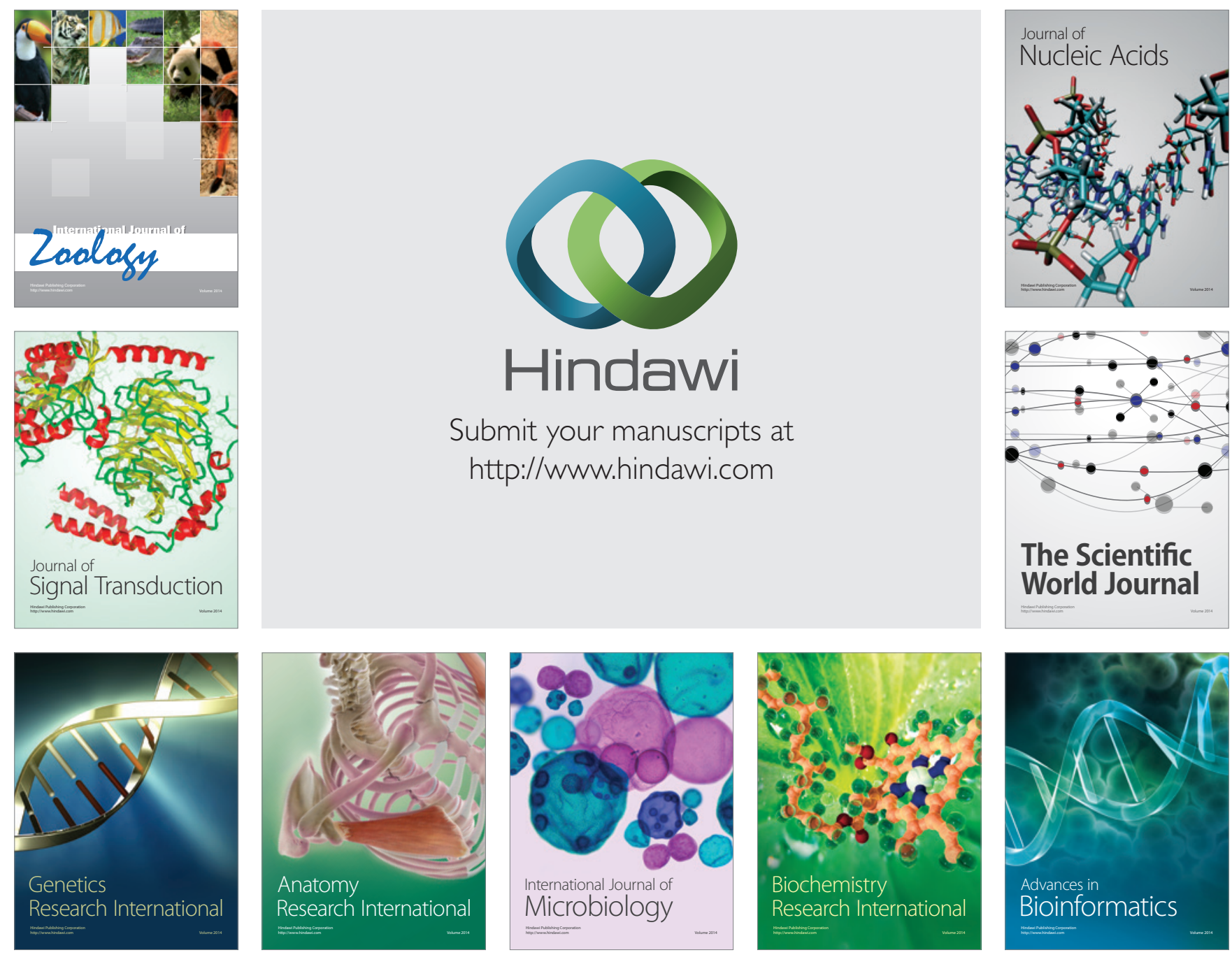

The Scientific World Journal
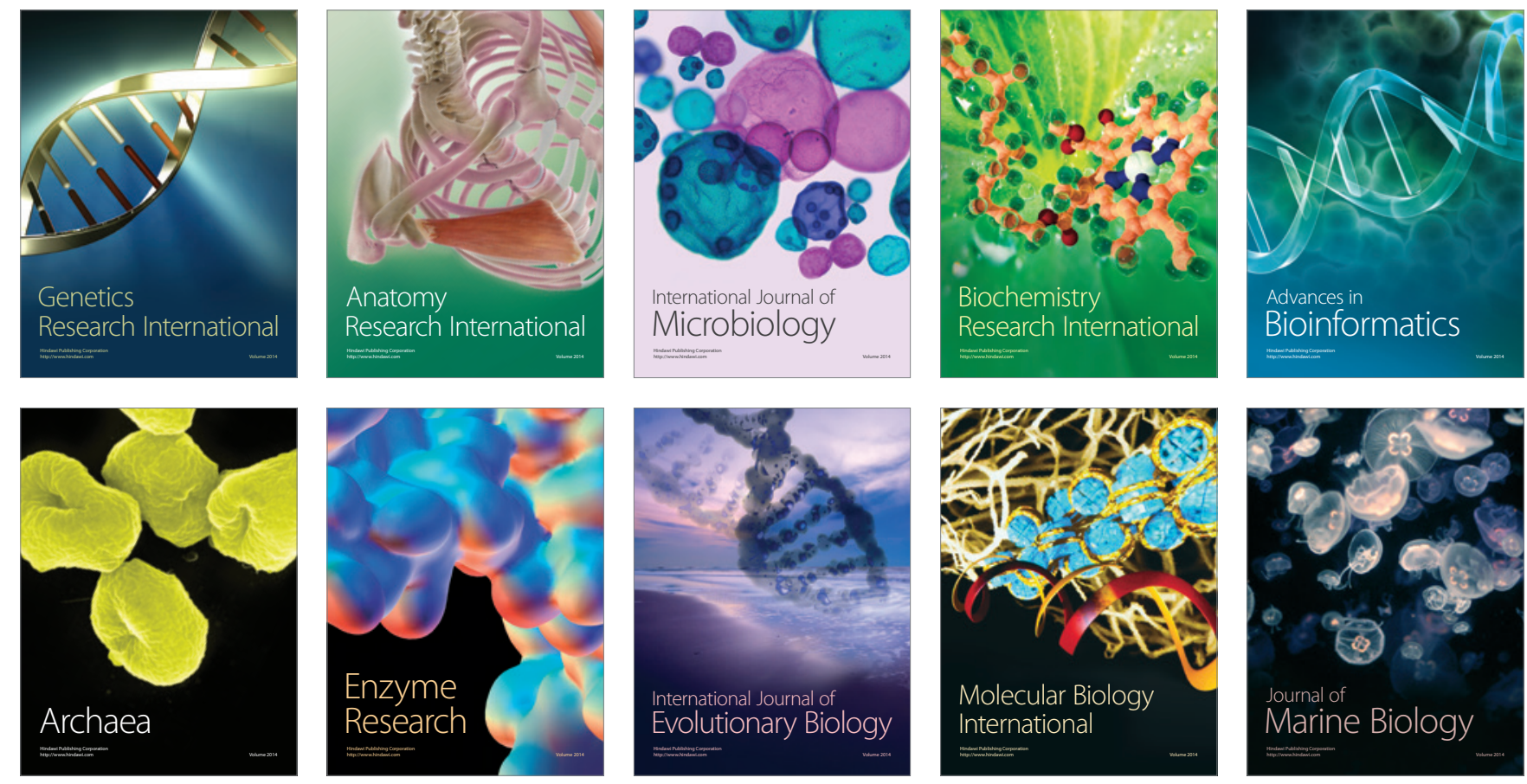